\title{
滇东湖泊水生植物和浮游生物碳、氮稳定同位素与元素组成特征
}

\author{
梁 红, 黄林培**,陈光杰, 康文刚, 刘园园, 王教元, 朱庆生, 刘 术, 邓颖 \\ (云南师范大学旅游与地理科学学院, 高原地理过程与环境变化云南省重点实验室, 昆明 650500)
}

\begin{abstract}
摘 要: 稳定同位素示踪方法是研究生态系统组成与功能的重要手段,有助于认识湖泊食物网的基本组成与生物地球化 学循环的主要过程. 本研究选择了云南省东部地区营养水平不同的 10 个湖泊,开展了高等水生植物 (沉水植物、漂浮植 物)、浮游植物与浮游动物的空间调查, 分析了不同生物在碳、氮稳定同位素信号与元素组成上的分布模式. 在碳稳定同 位素信号的分布上, 漂浮植物在 4 种生物类型中最为偏负且变化幅度最小, 为 $-28.99 \% 0 \pm 0.86 \%$; 浮游动物碳稳定同位素 $(-20.85 \% \pm 2.70 \% 0)$ 的分布特征与浮游植物 $(-21.88 \% 0 \pm 2.97 \% 0)$ 显著相似; 而沉水植物的碳稳定同位素显著偏正且变化 范围较大, 平均值为 $-12.04 \% \pm 4.57 \%$. 结果表明, 碳源及其传输途径的差异是导致湖泊生物体内碳同位素信号不同的主 要驱动过程. 在氮稳定同位素信号上, 同为初级生产者的沉水植物 $(5.43 \% 0 \pm 5.84 \% 0)$ 、漂浮植物 $\left(5.58 \%{ }_{0} \pm 7.38 \% 0\right)$ 与浮游植 物 ( 7.26\% $03.83 \% 0$ ) 较为相似, 而浮游动物氮同位素信号 $(11.02 \% 0 \pm 3.18 \% 0$ ) 显著高于浮游植物且平均富集约 $3.46 \% 0$, 反映 了湖泊生物随着营养级的增加出现较为明显的同位素分馏效应. 在空间分布上, 湖泊生物碳同位素信号受到水温、水深 等因素的明显影响,氮同位素信号则随湖泊营养水平的增加而逐渐偏正. 与长江中下游等地区相比,云南湖泊生物的碳、 氮元素含量总体偏高; 同时, 代表内源有机质组分的水生植物和浮游生物 $\mathrm{C} / \mathrm{N}$ 质量比值都小于 20 . 因此, 本研究揭示的生 物碳、氮同位素信号与元素组成特征可为评价高原湖泊食物网组成与生物地球化学循环提供重要的科学依据.
\end{abstract}

关键词 : 碳、氮稳定同位素;水生生物;营养级;富营养化;云南湖泊

\section{Patterns of carbon and nitrogen stable isotopes and elemental composition of lake primary producers and zooplankton in Eastern Yunnan}

LIANG Hong, HUANG Linpei ${ }^{* *}$, CHEN Guangjie, KANG Wengang, LIU Yuanyuan, WANG Jiaoyuan, ZHU Qingsheng, LIU Shu \& DENG Ying

(Yunnan Province Key Laboratory of Plateau Geographical Processes and Environmental Change, School of Tourism and Geography, Yunnan Normal University, Kunming 650500, P.R.China)

Abstract: Stable isotope method serves as an important means to uncover the ecosystem structure and functioning, and to reveal the composition of lake food webs and the processes for biogeochemical cycling. In this study, a spatial survey of ten lakes with different nutrient levels in Eastern Yunnan was conducted through analyzing the carbon and nitrogen stable isotopes and elemental composition for aquatic plants ( submerged macrophyte, floating plant), phytoplankton and zooplankton, respectively. The result shows that, among the four groups of lake organisms, floating plant has the most negative signal of stable carbon isotope, with a mean value $( \pm$ SD $)$ of $-28.99 \% \pm 0.86 \%$. While phytoplankton $(-21.88 \% \pm 2.97 \%$ o $)$ and zooplankton $(-20.85 \% \pm 2.70 \%$ are characterized by similar carbon isotope values, the submerged macrophyte has a large variation with significantly more positive $\delta^{13} \mathrm{C}$ value $(-12.04 \% \pm 4.57 \%$ ). This indicates that the difference in carbon sources absorbed or utilized has caused the deviation in stable carbon isotope composition among these four organisms. In terms of stable nitrogen isotope, the primary producers, including submerged macrophyte $\left(5.43 \% \pm \pm 5.84 \%\right.$ ) , floating plant $\left(5.58 \% 0 \pm 7.38 \%\right.$ ) and phytoplankton $\left(7.26 \% \%^{\circ} \pm .83 \%\right.$ ) , show significantly similar $\delta^{15} \mathrm{~N}$ values. While the $\delta^{15} \mathrm{~N}$ value of primary consumer, zooplankton $(11.02 \% \pm 3.18 \%$, is significantly higher with a averaged enrichment factor by $3.46 \%$, indicating the effect of nitrogen isotope fractionation across trophic levels in our lakes. Furthermore, the carbon isotope signal of lake organisms are also affected by factors such as water temperature and water depth. The varia-

* 国家自然科学基金项目 (41302151, 41771239, 31460131, U1133601)资助. 2017-11-05 收稿;2018-01-02 收修改 稿. 梁红(1992 ), 女, 硕士研究生;E-mail: liangred1@163.com.

** 通信作者;E-mail: bacon768376@126.com. 
tion in the nitrogen isotope signal is dominated by lake eutrophication, which leads to a gradual enrichment in the organismal signal of $\delta^{15} \mathrm{~N}$. In addition, the carbon and nitrogen content of aquatic organisms from Yunnan lakes are higher than those in lakes from the middle and lower reaches of the Yangtze River. There existed a threshold $\mathrm{C} / \mathrm{N}$ ratio of primary producers and primary consumers in defining the shift between autochtonous and allothonous sources of organic matter in our lakes. This spatial survey provided important data for understanding the food web composition and biochemical cycling for plateau lakes.

Keywords: Carbon and nitrogen stable isotopes; aquatic organism; trophic level; eutrophication; Yunnan lakes

人类活动的增强已显著改变了区域与全球尺度上生物地球化学循环的时空模式,导致了自然环境功能 退化、生物多样性减少、生态系统结构变化等严重的生态环境问题 ${ }^{[1]}$. 目前, 水体富营养化是我国部分湖泊 面临的主要环境问题之一,其导致了水质恶化、生态系统服务功能退化和生态系统健康下降 ${ }^{[2]}$.

初级生产者与初级消费者是淡水生态系统结构的重要组成 ${ }^{[3-5]}$, 是维持系统生产力、多样性和稳定性功 能的基础 ${ }^{[6]}$. 其中, 高等水生植物和浮游植物作为湖泊生态系统中的主要初级生产者, 是维持湖泊生态结构 和功能的重要组分. 富营养水体中常出现浮游植物的大量繁殖, 同时沉水植物等高等水生植物群落结构退 化、覆盖度下降, 可以导致湖泊生态系统由草型湖泊向藻型湖泊的稳态转变 ${ }^{[7-8]}$. 浮游动物在湖泊生态系统 的物质和能量循环中起到承上启下的作用,即捕食浮游植物的同时又作为更高一级消费者 (如鱼类) 的主要 食物 ${ }^{[9]}$. 因此, 湖泊初级生产者和初级消费者在湖泊系统的碳、氮等元素循环过程中起到了重要的储存与传 递作用,可以反映湖泊生物地球化学循环的传递过程及其变化.

稳定同位素示踪技术已广泛应用于生态学研究中, 探讨不同生态系统中物质和能量流动的主要特征和 循环路径 ${ }^{[10]}$. 高等水生植物、浮游植物、浮游动物作为生产者和初级消费者能直接记录湖泊营养源的变化 特征 ${ }^{[11]}$, 同时利用生物体内的碳、氮稳定同位素信号能定量区分食物网中的主要碳源和不同生物的营养级 水平 ${ }^{[12-13]}$, 是了解湖泊生态系统中碳、氮等元素循环与传递过程的重要分析手段. Grey ${ }^{[14]}$ 和 Noochera 等 ${ }^{[15]}$ 利用稳定同位素示踪技术研究发现,湖泊营养水平的上升增强了浮游植物和浮游动物在有机碳传输过程上 的耦合, 导致了浮游植物和浮游动物碳同位素的同步富集且呈现显著相似的信号. 目前国内关于湖泊生物 碳、氮稳定同位素的研究较多关注于大型湖泊等水体. 如 Wen 等 ${ }^{[16]}$ 测定了太湖贡湖湾和梅梁湾的高等水生 植物碳、氮同位素的时空变化特征, 结果表明, 沉水植物碳稳定同位素值较高, 漂浮植物与挺水植物碳稳定 同位素值偏低,营养水平较高的梅梁湾中沉水植物氮稳定同位素值信号明显高于贡湖湾, 而时间变化规律 总体上并无明显特征. 黄亮等 ${ }^{[17]}$ 调查长江中游 9 个湖泊水生植物 $C 、 N 、 P$ 元素及碳同位素, 发现植物叶片中 的碳稳定同位素值和 $\mathrm{C} 、 \mathrm{~N}$ 元素与其所处的水环境特征密切相关. 徐军 ${ }^{[18]}$ 对比了云南星云湖和抚仙湖颗粒 有机物的碳、氮同位素信号,发现星云湖颗粒有机物的碳、氮同位素均高于抚仙湖,表明碳、氮稳定同位素的 空间差异反映了湖泊营养水平的不同.

综上所述, 国内已有研究中对湖泊多个生物门类开展碳、氮稳定同位素的对比研究较少, 目前围绕云南 湖泊水生植物和浮游生物的碳、氮同位素信号特征及其分布模式的区域调查还未见报道. 基于此,本研究选 择云南省东部地区 10 个湖泊, 以高等水生植物、浮游植物和浮游动物作为研究对象, 通过测定湖泊不同生 物类别的碳、氮稳定同位素信号及元素组成, 有助于识别云南高原湖泊典型水生生物在元素循环过程中的 同位素分馏效应和元素含量的空间变化规律及其生态指示意义.

\section{1 研究区概况与研究方法}

\section{1 研究区概况}

滇东位于云南省东部,整体位于扬子准地台与华南禇皱系的西隅, 地势北高南低, 碳酸盐广泛分布 ${ }^{[19]}$. 属于北热带气候类型 ${ }^{[20]}$, 本次调查湖泊 (图 1) 平均降水量为 717.60 $983.00 \mathrm{~mm}$; 其中星云湖、杞麓湖为断陷 湖, 月湖、长湖是喀斯特溶蚀湖, 三角海、异龙湖、差黑海已发展为水库. 星云湖平均水深最大, 为 $6.01 \mathrm{~m}$; 杞 麓湖湖泊面积最大, 为 $36.95 \mathrm{~km}^{2}$, 相反, 草甸海湖面面积最小, 为 $1.30 \mathrm{~km}^{2[21]}$; 调查湖泊中湖面海拔梯度为 1280.83 1908.41 m(表 1). 研究的湖泊多数位于盆地中, 河流径流短, 汇水面积小, 多数湖泊仅有一条出口 河流. 受高原气候的影响, 湖面蒸发量常高于湖面降水量. 整体而言, 湖泊高水位一般出现在 9-12 月,最低 水位出现在 5-6 月. 滇东 10 个湖泊整体环境较好,但部分湖泊随着湖区周边工农业生产的发展以及人口 
数量的增加, 出现湖泊水位下降、湖面面积缩小、水体污染严重、生物多样性锐减等问题. 比如, 星云湖湖泊 污染较严重、水生植物覆盖度低,已成为重富营养水平的湖泊 ${ }^{[22]}$, 星云湖、大屯海、杞麓湖、长桥海和异龙湖 湖泊水体也受到了不同程度的污染, 月湖、长湖、差黑海等湖泊水体透明度较高, 生长的高等水生植物种类 较多.

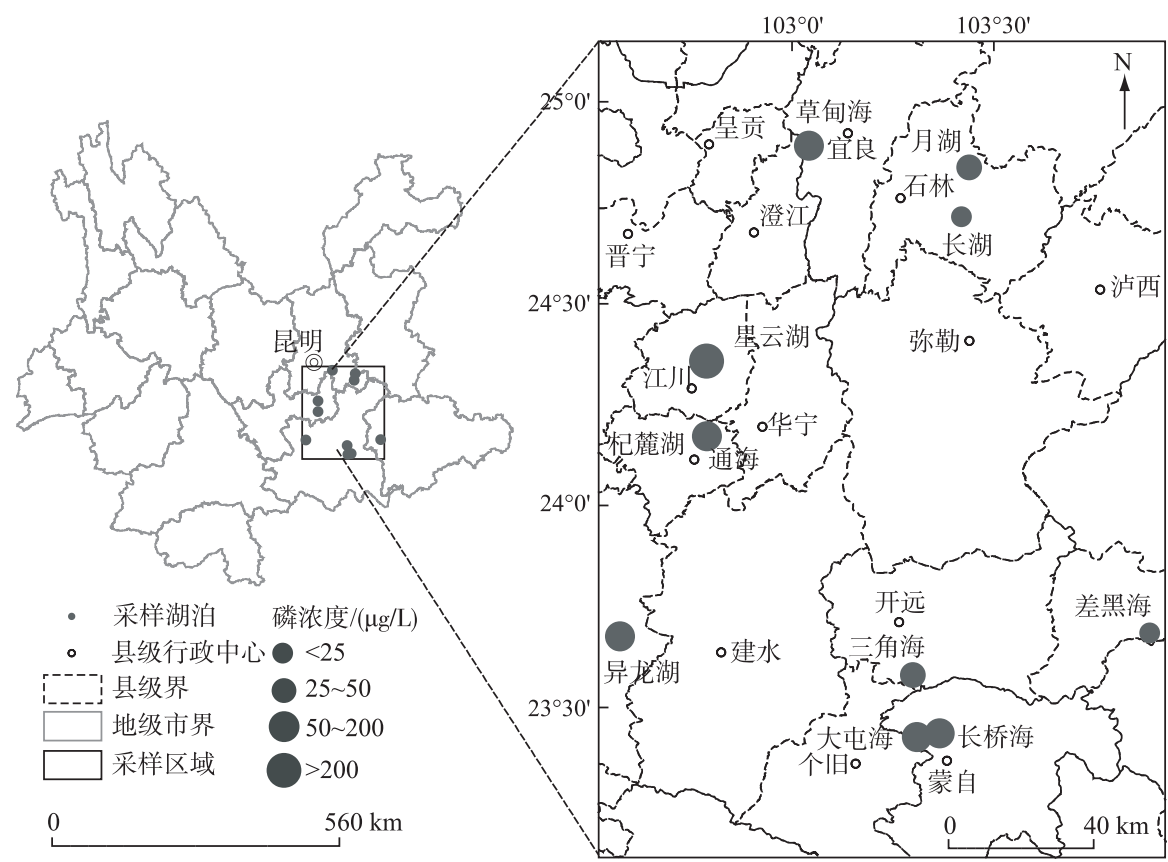

图 1 滇东地区 10 个采样湖泊分布

Fig.1 Map showing the ten study lakes in Eastern Yunnan

表 1 滇东 10 个湖泊位置坐标及其他相关信息

Tab.1 Summary of site location and key catchment features of ten study lakes in Eastern Yunnan

\begin{tabular}{cccccc}
\hline 湖泊 & 坐标位置 & $\begin{array}{c}\text { 流域面积/湖泊面积/ } \\
\mathrm{km}^{2}\end{array}$ & $\begin{array}{c}\text { 最大/平均 } \\
\text { 水深/m }\end{array}$ & $\begin{array}{c}\text { 湖面 } \\
\text { 高程 } / \mathrm{m}\end{array}$ & $\begin{array}{c}\text { 年降水 } \\
\text { 量 } / \mathrm{mm}\end{array}$ \\
\hline 星云湖 & $24^{\circ} 17^{\prime} \sim 24^{\circ} 23^{\prime} \mathrm{N}, 102^{\circ} 45^{\prime} \sim 102^{\circ} 48^{\prime} \mathrm{E}$ & $378.00 / 34.33$ & $10.81 / 6.01$ & 1725.05 & 947.00 \\
大屯海 & $23^{\circ} 23^{\prime} \sim 23^{\circ} 27^{\prime} \mathrm{N}, 103^{\circ} 18^{\prime} \sim 103^{\circ} 20^{\prime} \mathrm{E}$ & $284.50 / 12.30$ & $2.70 / 1.30$ & 1281.68 & 717.60 \\
杞麓湖 & $24^{\circ} 08^{\prime} \sim 24^{\circ} 13^{\prime} \mathrm{N}, 102^{\circ} 43^{\prime} \sim 102^{\circ} 49^{\prime} \mathrm{E}$ & $341.0 / 36.95$ & $6.84 / 4.20$ & 1799.42 & 869.20 \\
草甸海 & $24^{\circ} 54^{\prime} \mathrm{N}, 103^{\circ} 03^{\prime} \mathrm{E}$ & $-/ 1.30$ & $4.00 / 2.50$ & 1859.33 & 963.50 \\
长桥海 & $23^{\circ} 24^{\prime} \sim 23^{\circ} 27^{\prime} \mathrm{N}, 103^{\circ} 20^{\prime} \sim 103^{\circ} 24^{\prime} \mathrm{E}$ & $167.00 / 10.70$ & $5.50 / 3.74$ & 1291.08 & 834.20 \\
异龙湖 & $23^{\circ} 38^{\prime} \sim 23^{\circ} 42^{\prime} \mathrm{N}, 102^{\circ} 30^{\prime} \sim 102^{\circ} 38^{\prime} \mathrm{E}$ & $303.60 / 29.59$ & $5.70 / 3.90$ & 1414.17 & 928.00 \\
三角海 & $23^{\circ} 34^{\prime} \sim 23^{\circ} 36^{\prime} \mathrm{N}, 103^{\circ} 18^{\prime} \sim 103^{\circ} 20^{\prime} \mathrm{E}$ & $131.20 / 3.33$ & $10.00 /-$ & 1280.83 & 800.00 \\
月湖 & $24^{\circ} 50^{\prime} \mathrm{N}, 103^{\circ} 27^{\prime} \mathrm{E}$ & $-/ 3.00$ & $-/ 3.50$ & 1908.41 & 960.00 \\
差黑海 & $23^{\circ} 41^{\prime} \mathrm{N}, 103^{\circ} 53^{\prime} \mathrm{E}$ & $34.80 / 2.40(2013)$ & $-/-$ & 1452.68 & 983.00 \\
长湖 & $24^{\circ} 43^{\prime} \mathrm{N}, 103^{\circ} 25^{\prime} \mathrm{E}$ & $-/ 1.50$ & $-/ 2.40$ & 1895.64 & 960.00 \\
\hline
\end{tabular}

一表示无数据.

\section{2 样品采集与处理}

2016 年 7 月底至 8 月初集中对滇东 10 个湖泊开展湖泊水质与生物的野外调查. 根据湖泊大小, 分别在 星云湖、异龙湖和长桥海布置 $4 、 3$ 和 7 个采样点, 其余湖泊均布置 2 个采样点. 分别采集了湖泊表层水样、高 
等水生植物、浮游植物和浮游动物, 共计 173 个样品. 在湖泊沿岸带主要采集沉水植物和漂浮植物. 沉水植 物以篦齿眼子菜 (Potamogeton pectinatus)、光叶眼子菜 (Potamogeton lucens)、微齿眼子菜 (Potamogeton maackianus)、穿叶眼子菜 (Potamogeton perfoliatus)、穗状狐尾藻 (Myriophyllum spicatum) 、小茨藻 ( Najas minor)、黑 藻 (Hydrilla verticillata)、狸藻 (Utricularia vulgaris) 为代表. 漂浮植物以大薸 (Pistia stratiotes)、凤眼蓝 (Eichhornia crassipes $)$ 为代表. 将采集的水生植物清洗干净风干后带回实验室, 用 $10 \%$ 盐酸酸化处理, 然后用蒸馏 水清洗干净, $60^{\circ} \mathrm{C}$ 下烘干, 磨成粉末后待测. 浮游植物和浮游动物样品使用采水器采集, 分别经 22 和 $64 \mu \mathrm{m}$ 孔径网篮过滤, 得到的浮游动物 (个体> $64 \mu \mathrm{m}$ ) 和浮游植物样品 (大小为 $22 \sim 64 \mu \mathrm{m}$ ) 低温保存. 样品带回实 验室后, 将浮游植物、浮游动物样品装人玻璃血中进行镜检并挑出杂质, $10 \%$ 盐酸酸化处理, 以去除浮游植 物、浮游动物体内可能存在的无机碳, 用蒸馏水清洗干净, 在 $-50^{\circ} \mathrm{C}$ 下冻干至恒重后磨成均匀粉末待测.

用采水器采集表层水样并低温保存. 在野外使用 $\mathrm{GF} / \mathrm{C}$ 玻璃纤维滤膜 $(0.45 \mu \mathrm{m})$ 过滤水样, 滤膜用于测 定叶绿素a (Chl.a) 浓度. Chl.a 浓度采用丙酮萃取分光光度法测定; 总氮 (TN) 浓度采用碱性过硫酸钾消解紫 外分光光度法测定; 总磷 (TP) 浓度采用钿锑抗分光光度法测定 ${ }^{[23]}$. 湖泊水化学指标均用紫外分光光度计 (UV1750) 测定. 湖泊水温、 $\mathrm{pH}$ 等用 YSI 6600 测定; 透明度用塞氏盘测定; 采样点水深用手持式水深仪测定.

\section{3 稳定同位素分析}

高等水生植物、浮游植物、浮游动物样品用美国 Thermo Scientific 的 MAT 253 气体稳定同位素比质谱仪 联用 Flash EA 元素分析仪, 采用快速燃烧法测定样品碳、氮同位素组成 $\left(\delta^{13} \mathrm{C} 、 \delta^{15} \mathrm{~N}\right)$ 和总碳 $(\mathrm{TC}) 、 \mathrm{TN}$ 含量. 稳定 $\mathrm{C} 、 \mathrm{~N}$ 同位素计算公式为:

$$
\delta X(\%)=\left(\frac{R_{\text {sample }}}{R_{\text {standard }}}-1\right) \times 1000
$$

式中, $X$ 表示 ${ }^{13} \mathrm{C}$ 或 ${ }^{15} \mathrm{~N}, R_{\text {sample }}$ 为样品 ${ }^{13} \mathrm{C} /{ }^{12} \mathrm{C}$ 或 ${ }^{15} \mathrm{~N} /{ }^{14} \mathrm{~N}, R_{\text {standard }}$ 为标样 ${ }^{13} \mathrm{C} /{ }^{12} \mathrm{C}$ 或 ${ }^{15} \mathrm{~N} /{ }^{14} \mathrm{~N}$, 分析精度 $<0.1 \%$. 样 品测试在云南师范大学高原地理过程与环境变化云南省重点实验室完成.

\section{4 数据处理}

进行统计分析前对数据进行正态分布检验与数据转换的预处理, 应用 Student's $t$-test 检验 ${ }^{[24]}$ 方法进行 差异显著性检验, 所有统计分析均在 $\mathrm{R}$ 软件 ${ }^{[25]}$ 和 Grapher 9 中进行, 本文所有数据均为平均值 \pm 标准差.

\section{2 结果与分析}

\section{1 基本水化学参数}

滇东 10 个湖泊采样时表层平均水温为 $23.27 \sim 30.40^{\circ} \mathrm{C}$; 各湖泊采样点平均水深为 $2.80 \sim 8.55 \mathrm{~m}$, 其中星 云湖、三角海、长湖、差黑海中各采样点平均水深在 $5.00 \mathrm{~m}$ 以上, 大屯海采样点平均水深最低, 小于 $3.00 \mathrm{~m}$; 水体平均透明度为 $0.23 \sim 2.10 \mathrm{~m}$, 其中月湖、长湖、差黑海水体透明度较高, 大于 $1.00 \mathrm{~m}$, 异龙湖、大屯海、长 桥海、星云湖和杞麓湖水体透明度较低, 低于 $0.50 \mathrm{~m}$; 湖泊水体平均 TP 浓度为 $13.27 \sim 547.88 \mu \mathrm{g} / \mathrm{L}$, 其中星 云湖 TP 平均含量最高, 长湖最低. 各湖泊水体平均 TN 浓度为 $0.53 \sim 3.40 \mathrm{mg} / \mathrm{L}$, 其中杞麓湖和异龙湖平均 $\mathrm{TN}$ 浓度超过 $3.00 \mathrm{mg} / \mathrm{L}$; 各湖泊水体 Chl.a 浓度为 $3.35 \sim 200.46 \mu \mathrm{g} / \mathrm{L}$, 星云湖最高, 超过 $200.00 \mu \mathrm{g} / \mathrm{L}$, 其次为 大屯海、杞麓湖、长桥海, Chl. a 平均浓度超过 $100.00 \mu \mathrm{g} / \mathrm{L}$, 湖泊初级生产力高. 根据世界经济协作与发展组 织 (OECD) 提出的湖泊营养状况分类标准 ${ }^{[26]}$ 并综合所有水质参数数据表明, 星云湖属于重富营养湖泊, 大 屯海、杞麓湖、草甸海、长桥海和异龙湖属于富营养湖泊, 三角海、月湖属于中一富营养湖泊, 而长湖、差黑海 属于中营养湖泊 (表 2).

\section{2 水生生物 $\delta^{13} \mathrm{C}$ 和 $\delta^{15} \mathrm{~N}$ 分布特征}

此次调查的滇东湖泊水 4 种类型的水生生物 $\delta^{13} \mathrm{C}$ 和 $\delta^{15} \mathrm{~N}$ 存在明显差异 (图 2). 沉水植物的平均 $\delta^{13} \mathrm{C}$ 值变化范围较大, 且显著高于其他 3 类水生生物的同位素值, 平均值为 $-12.04 \% 0 \pm 4.57 \%$; 沉水植物的 $\delta^{15} \mathrm{~N}$ 平均值为 $5.43 \% 0 \pm 5.84 \% 0$, 变化范围也相对较广. 漂浮植物的 $\delta^{13} \mathrm{C}$ 值较稳定且最为偏负, 为 $-28.99 \% 0 \pm$ $0.86 \%$, 而 $\delta^{15} \mathrm{~N}$ 值波动幅度大, 为 $5.58 \% 0 \pm 7.38 \%$; 浮游植物的 $\delta^{13} \mathrm{C}$ 值与浮游动物相似, 平均值分别为 $-21.88 \% 0 \pm 2.97 \%$ 和 $-20.85 \% 0 \pm 2.70 \%$, 而浮游植物的 $\delta^{15} \mathrm{~N}$ 值为 $7.26 \% 0 \pm 3.83 \% 0$, 浮游动物 $\delta^{15} \mathrm{~N}$ 值更高, 为 $11.02 \% 0 \pm 3.18 \% . t$ 检验结果表明, 沉水植物和漂浮植物的 $\delta^{13} \mathrm{C}$ 与浮游植物和浮游动物的存在显著差异 
表 2 采样湖泊湖沼学基本特征

Tab.2 Key limnological characteristics of ten study lakes

\begin{tabular}{ccccccc}
\hline 湖泊 & ${\text { 水温 } /{ }^{\circ} \mathrm{C}}$ & 水深 $/ \mathrm{m}$ & 透明度 $/ \mathrm{m}$ & 总磷 $/(\mu \mathrm{g} / \mathrm{L})$ & 总氮 $/(\mathrm{mg} / \mathrm{L})$ & 叶绿素 $\mathrm{a} /(\mu \mathrm{g} / \mathrm{L})$ \\
\hline 星云湖 & $24.33 \pm 0.19$ & $8.55 \pm 1.88$ & $0.39 \pm 0.02$ & $547.88 \pm 57.14$ & $2.93 \pm 0.83$ & $200.46 \pm 111.88$ \\
大屯海 & $30.40 \pm 0.14$ & $2.80 \pm 0.28$ & 0.25 & $96.95 \pm 3.94$ & $2.93 \pm 0.05$ & $155.02 \pm 38.70$ \\
杞麓湖 & $23.27 \pm 0.21$ & $4.77 \pm 0.38$ & $0.39 \pm 0.01$ & $95.85 \pm 6.30$ & $3.18 \pm 0.09$ & $108.17 \pm 8.58$ \\
草甸海 & $23.60 \pm 0.13$ & $3.95 \pm 0.35$ & $0.43 \pm 0.04$ & $84.99 \pm 1.02$ & $1.81 \pm 0.01$ & $74.43 \pm 3.80$ \\
长桥海 & $28.20 \pm 1.78$ & $3.72 \pm 0.57$ & $0.28 \pm 0.03$ & $78.45 \pm 9.28$ & $2.69 \pm 0.17$ & $138.74 \pm 8.93$ \\
异龙湖 & $25.75 \pm 0.28$ & $3.67 \pm 0.42$ & $0.23 \pm 0.02$ & $63.36 \pm 0.08$ & $3.40 \pm 0.62$ & $95.71 \pm 13.13$ \\
三角海 & $27.95 \pm 0.64$ & $6.90 \pm 0.28$ & $0.41 \pm 0.05$ & $47.74 \pm 3.79$ & $1.45 \pm 0.33$ & $59.62 \pm 4.68$ \\
月湖 & $23.35 \pm 0.49$ & $4.85 \pm 1.20$ & $1.05 \pm 0.07$ & $44.61 \pm 26.16$ & $0.58 \pm 0.01$ & 10.40 \\
差黑海 & 27.95 & $5.20 \pm 0.28$ & 2.10 & $24.11 \pm 6.86$ & $0.53 \pm 0.03$ & $3.35 \pm 0.76$ \\
长湖 & $24.50 \pm 0.14$ & $5.55 \pm 2.05$ & $2.05 \pm 0.21$ & $13.27 \pm 0.15$ & $0.59 \pm 0.14$ & $3.68 \pm 0.22$ \\
\hline
\end{tabular}
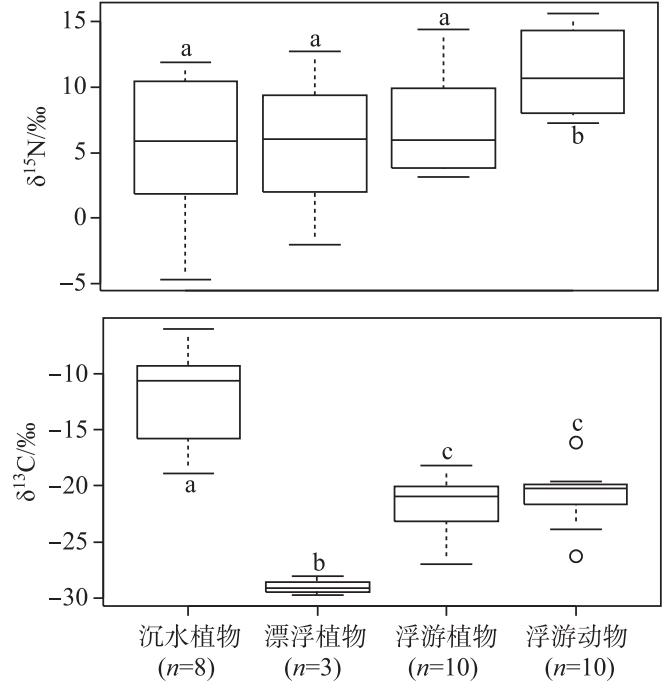

图 24 种水生生物氮、碳稳定同位素信号分布特征

(箱线图上下两条短线表示数据范围,箱子包含 中间 $50 \%$ 的数据,箱子中横线为中位数, 空心小圆圈表示异常值; $n$ 表示湖泊数量; 不同字母表示显著差异,$P<0.05$ )

Fig.2 Boxplot showing the distribution of nitrogen and carbon isotopes of four biological groups

( The box included $50 \%$ of the observational data. Lines extending vertically from the boxes indicating variability outside the upper and lower quartiles. The band inside the box indicates the median value. The outliers ( circle) are observational data that are distant from other points.

The letter $n$ denotes number of sampling lakes.

The boxes with different letters show a significant difference with $P$-value less than 0.05 )
$(P<0.05)$, 浮游植物和浮游动物的 $\delta^{13} \mathrm{C}$ 差异不显著 $(P>0.05)$; 初级生产者漂浮植物、沉水植物和浮游植 物的 $\delta^{15} \mathrm{~N}$ 值差异不显著 $(P>0.05)$, 而初级消费者浮 游动物的 $\delta^{15} \mathrm{~N}$ 值则与 3 类初级生产者存在显著差异 $(P<0.05)$. 湖泊中浮游植物与浮游动物 $\delta^{13} \mathrm{C}$ 值和 $\delta^{15} \mathrm{~N}$ 值之间具有很好的线性关系 (图 3), 决定系数 $R^{2}$ 分 别为 $0.80(P>0.05)$ 和 $0.74(P<0.001)$, 表明浮游动物 的 $\delta^{13} \mathrm{C}$ 值和 $\delta^{15} \mathrm{~N}$ 值对浮游植物的变化最为敏感.

\section{3 水生生物碳、氮稳定同位素信号的空间变化特征}

区域尺度上, 调查的 10 个滇东湖泊浮游动物和 浮游植物 $\delta^{13} \mathrm{C}$ 值的变化趋势基本一致, 浮游动物 $\delta^{13} \mathrm{C}$ 值整体略高于浮游植物, 尤其在中营养湖泊 (长 湖、差黑海) 和中一富营养湖泊 (三角海、月湖) 中表现 明显, 而在重富营养湖泊 (星云湖) 中浮游动物和浮 游植物 $\delta^{13} \mathrm{C}$ 值基本重叠 (图 4). 氮同位素组成方面, 浮游植物和浮游动物的 $\delta^{15} \mathrm{~N}$ 变化曲线具有同步性, 但在同一湖泊中, 浮游动物 $\delta^{15} \mathrm{~N}$ 值较浮游植物显著 偏正, 富集程度为 $1.2 \% 0 \sim 6.8 \%$, 平均富集 3.46\%左右 (图 $3 \mathrm{~b}$ 和图 4). 沉水植物 $\delta^{13} \mathrm{C}$ 值波动范围较大, 且 在区域尺度上无明显变化趋势, 但其 $\delta^{15} \mathrm{~N}$ 值与浮游 植物、浮游动物的变化模式一致, 即随湖泊富营养化 程度的增加而逐渐偏正. 漂浮植物在多数湖泊未采集 到,因此不做空间变化分析.

为了探讨不同环境因子与不同湖泊生物碳、氮稳 定同位素之间的关系, 我们对滇东 10 个湖泊生物碳、 氮同位素数据做了主成分分析 (PCA). 零模型检验 结果表明, 影响滇东 10 个湖泊浮游植物与浮游动物 $\delta^{13} \mathrm{C}$ 和 $\delta^{15} \mathrm{~N}$ 变化的显著 PCA 轴有两个, 分别解释了 $32.06 \%$ 和 $23.50 \%$ (图 5a). 驱动沉水植物 $\delta^{13} \mathrm{C}$ 和 $\delta^{15} \mathrm{~N}$ 变化的显著 PCA 轴有一个, 解释了 $55.19 \%$ (图 $5 \mathrm{~b})$. 由图 $5 \mathrm{a}$ 可知, 湖泊水温和 $\mathrm{pH}$ 值是影响浮游植 

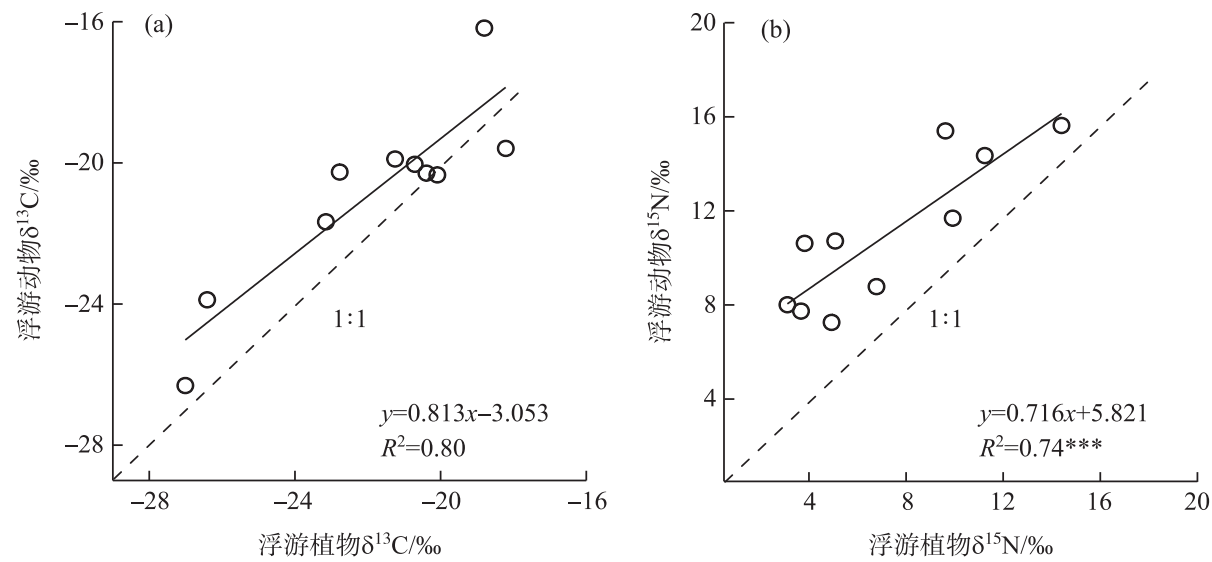

图 3 滇东湖泊的浮游植物与浮游动物碳、氮稳定同位素信号散点图 (数据为同一湖泊的平均值, 虚线表示 $1: 1$ 线,实线表示回归线,星号代表回归分析显著水平 $(* * *, P<0.001))$

Fig.3 Scatter plots showing the relationship between phytoplankton and zooplanktonfor carbon (a) and nitrogen (b) stable isotopes of lakes in Eastern Yunnan, respectively (Each circle represents the averaged $\delta{ }^{13} \mathrm{C}$ and $\delta^{15} \mathrm{~N}$ values of phytoplankton and zooplankton from one lake, respectively.

Dashed line indicates a $1: 1$ line. The solid line is drawn as the regression line.

The symbol *** represent a significant level with a $P$-value less than 0.001 )

物 $\delta^{13} \mathrm{C}$ 值在空间变化上的主要因子, 特别是水温 $(P<0.001, r=0.41)$, 其次, 浮游动物与浮游植物 $\delta^{13} \mathrm{C}$ 值矢 量方向呈锐角相交 $(P<0.01, r=0.76)$, 且与采样点水深呈反向变化关系. 浮游植物和浮游动物 $\delta^{15} \mathrm{~N}$ 的方向 一致, 与主轴 1 夹角最小. 主轴 1 与水体 TN、TP 浓度等指示湖泊富营养水平的指标密切相关 $(r=-0.80 、 r=$ $-0.62)$, 表明主轴 1 代表了湖泊富营养水平. 同时浮游植物和浮游动物 $\delta{ }^{15} \mathrm{~N}$ 值与水体 TN 、 TP 浓度呈显著正 相关关系 $(P<0.001, r=0.74 ; P<0.001, r=0.72 ; P<0.001, r=0.53 ; P<0.001, r=0.40)$, 指示浮游植物和浮游动 物的 $\delta{ }^{15} \mathrm{~N}$ 值受湖泊营养水平 (水体 TN 和 TP 浓度) 的驱动. 图 $5 \mathrm{~b}$ 显示, 沉水植物的 $\delta^{13} \mathrm{C}$ 值与湖泊水体透明 度呈负相关 $(P<0.01, r=-0.44)$, 而沉水植物 $\delta^{15} \mathrm{~N}$ 变化与水体 TN 浓度密切相关 $(P<0.001, r=0.52)$.

\section{$2.4 \mathrm{C} 、 \mathrm{~N}$ 元素含量和 $\mathrm{C} / \mathrm{N}$ 比值分布特征}

滇东 4 种湖泊生物具有不同的碳、氮 $(\mathrm{C} 、 \mathrm{~N})$ 元素含量, 沉水植物和漂浮植物的 $\mathrm{C}$ 元素含量明显高于浮 游植物和浮游动物, 相反浮游动物的 $\mathrm{N}$ 元素含量最高, 浮游植物次之, 高等水生植物最低 (表 3 ). 经 $t$ 检验得 出, 沉水植物和漂浮植物的 $\mathrm{C}$ 和 $\mathrm{N}$ 元素含量差异均不显著 $(P>0.05)$, 浮游植物与浮游动物 $\mathrm{C}$ 和 $\mathrm{N}$ 元素含量 也无显著差异 $(P>0.05)$, 而沉水植物和漂浮植物等高等水生植物的 $\mathrm{C} 、 \mathrm{~N}$ 元素含量则与浮游植物和浮游动 物等浮游生物具有显著差异 $(P<0.05)$.

表 34 种湖泊生物的总碳、总氮元素重量百分含量与碳氮比值的分布特征

Tab.3 Summary of percentage mass contents of C and N elements, and C/N ratios for four biological groups

\begin{tabular}{cccc}
\hline 生物类型 $($ 湖泊数) & 总碳百分含量 $/ \%$ & 总氮百分含量 $/ \%$ & 碳氮质量比 \\
\hline 沉水植物 $(n=8)$ & $40.31 \pm 2.53$ & $2.37 \pm 0.44$ & $18.39 \pm 3.79$ \\
漂浮植物 $(n=3)$ & $40.91 \pm 3.63$ & $2.05 \pm 1.23$ & $15.67 \pm 1.60$ \\
浮游植物 $(n=10)$ & $29.44 \pm 7.80$ & $3.96 \pm 1.34$ & $7.68 \pm 1.65$ \\
浮游动物 $(n=10)$ & $27.90 \pm 10.96$ & $4.83 \pm 2.73$ & $6.90 \pm 2.78$ \\
\hline
\end{tabular}

从表 3 可以看出, 沉水植物和漂浮植物 $\mathrm{C} / \mathrm{N}$ 比值最高, 而浮游植物和浮游动物 $\mathrm{C} / \mathrm{N}$ 比值明显偏低. 沉 水植物和漂浮植物以及浮游植物和浮游动物的 $\mathrm{C} / \mathrm{N}$ 比值均无显著差异 $(P>0.05)$, 而沉水植物和漂浮植物 的 $\mathrm{C} / \mathrm{N}$ 比值与浮游植物和浮游动物的则具有显著差异 $(P<0.05)$. 

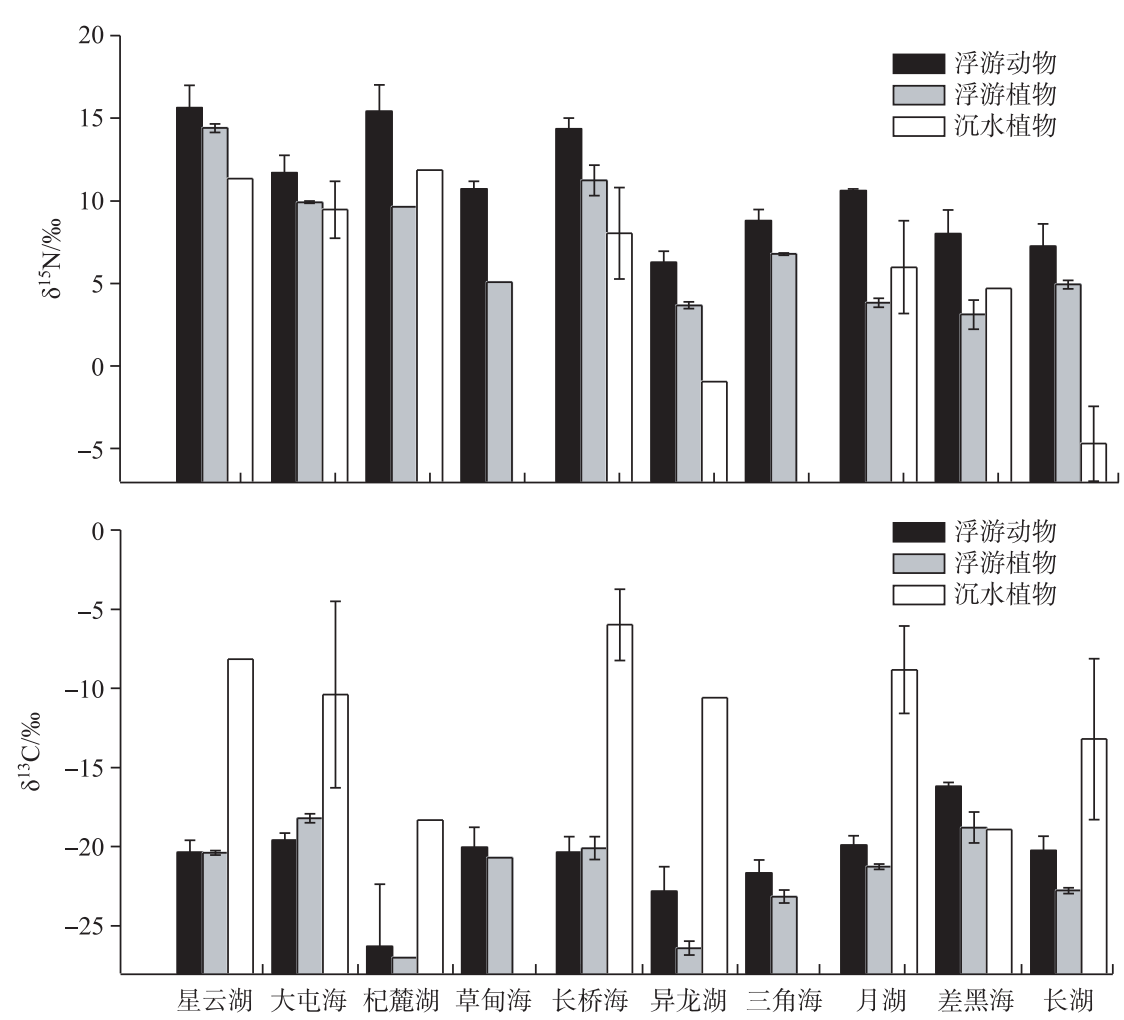

图 4 滇东湖泊的浮游植物、浮游动物与沉水植物碳、氮稳定同位素信号分布特征 (湖泊排序按水体总磷浓度由高到低排列)

Fig.4 Histograms showing the variation of carbon and nitrogen stable isotopes of three biological groups among lakes in Eastern Yunnan (Lakes are arranged according to the decreasing total phosphorus concentrations in lake water)

\section{3 讨论}

\section{1 滇东地区湖泊典型水生生物稳定同位素信号的特征比较}

滇东地区不同类型的湖泊生物具有不同的碳稳定同位素组成, 主要反映在生物利用的无机碳源比例存 在差异性. 就高等水生植物而言, 云南湖泊的沉水植物 $\delta^{13} \mathrm{C}$ 值比漂浮植物信号更为偏正, 且分布范围较广. 虽然沉水植物和漂浮植物均系维管植物, 但是两者具有不同的生长环境. 漂浮植物的根不生在底泥中, 整个 植株漂浮在水面之上, 发达的通气组织或膨大的叶柄能够保证它们与大气进行气体交换 ${ }^{[27]}$. 暴露在大气中 的漂浮植物叶片能够直接利用大气中的 $\mathrm{CO}_{2}$ 作为碳源, 使得大气中 $\mathrm{CO}_{2}$ 的 $\delta^{13} \mathrm{C}$ 值是影响漂浮植物 $\delta^{13} \mathrm{C}$ 值的 关键因素. 通常大气中 $\mathrm{CO}_{2}$ 的 $\delta^{13} \mathrm{C}$ 值稳定在 $-7.8 \%$ 左右 ${ }^{[28]}$, 因此漂浮植物的 $\delta^{13} \mathrm{C}$ 值也相对较为稳定, 变化 范围小. 而沉水植物整个植株完全沉没于水面之下, 根茎生于底泥中, 表皮细胞没有角质或蜡质层, 能直接 吸收水分、溶解氧和其他营养物质 ${ }^{[29]}$. 同时沉水植物所利用的底栖碳源来源较广, 包括碳酸氢盐 $\left(\mathrm{HCO}_{3}^{-}\right)$、 溶解在水中的 $\mathrm{CO}_{2}$ 和碳酸盐 $\left(\mathrm{CO}_{3}^{2-}\right) 3$ 种无机碳形式, 且 3 种形式无机碳的 $\delta^{13} \mathrm{C}$ 值组成变化大. 在进行光合 作用时, 由于 $\mathrm{CO}_{2}$ 被消耗所用的能量低, 因此溶解在水中的 $\mathrm{CO}_{2}$ 是最容易利用的碳源. 但是 $\mathrm{CO}_{2}$ 在水中的扩 散速度比在空气中小 4 个数量级, 在富营养水中溶解性的 $\mathrm{CO}_{2}$ 含量较低 ${ }^{[30]}$, 水体中无机碳离子常以 $\mathrm{HCO}_{3}^{-}$形 式存在 ${ }^{[31]}$. 并且已有研究表明, $\mathrm{HCO}_{3}^{-}$的 $\delta^{13} \mathrm{C}$ 值比 $\mathrm{CO}_{2}$ 的 $\delta^{13} \mathrm{C}$ 值高 7\%0 11\% ${ }^{[32-33]}$. 这些因素导致本次空间 调查中由于湖泊营养水平的不同, 水体中各种无机碳比例存在差异, 导致了沉水植物 $\delta^{13} \mathrm{C}$ 的变化幅度较大. 同时, 在同一湖泊的不同采样点, 同一种沉水植物由于利用的无机碳源比例不同, 也存在 $\delta^{13} \mathrm{C}$ 的明显差异. 

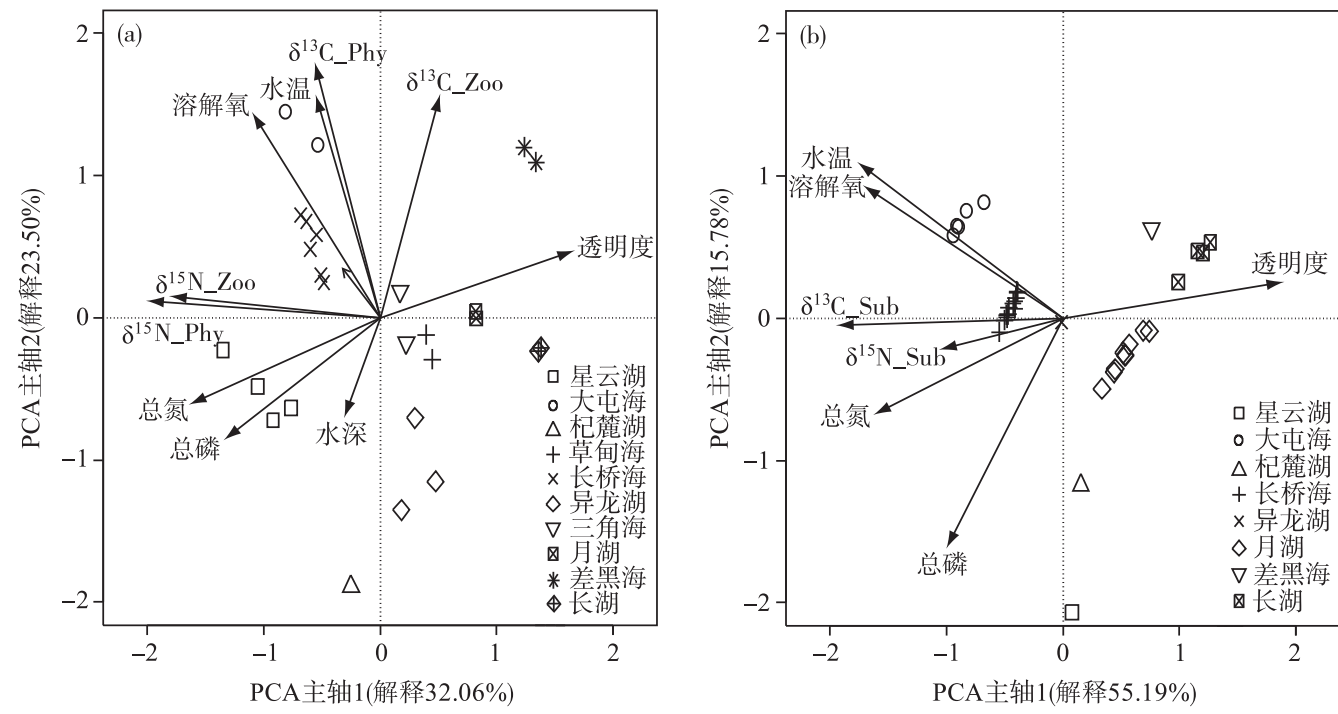

图 5 滇东湖泊浮游植物、浮游动物 (a) 和沉水植物 (b) 碳、氮稳定同位素与环境因子的 PCA 双图 $\left(\delta^{13} \mathrm{C} \_\right.$Phy : 浮游植物碳稳定同位素; $\delta^{13} \mathrm{C} \_$Z oo : 浮游动物碳稳定同位素; $\delta^{15} \mathrm{~N} \_P h y$ : 浮游植物氮稳定同位素; $\delta{ }^{15} \mathrm{~N} \_$Zoo : 浮游动物氮稳定同位素; $\delta^{13} \mathrm{C} \_$Sub : 沉水植物碳稳定同位素; $\delta^{15} \mathrm{~N} \_S u b:$ 沉水植物氮稳定同位素)

Fig.5 PCA biplots showing the carbon and nitrogen isotopes for phytoplankton, zooplankton (a) and submerged macrophyte (b) and related environmental factors among lakes in Eastern Yunnan

$\left(\delta^{13} \mathrm{C} \_\right.$Phy means the $\delta^{13} \mathrm{C}$ values of phytoplankton; $\delta^{13} \mathrm{C} \_$Zoo means the $\delta^{13} \mathrm{C}$ values of zooplankton;

$\delta^{15} \mathrm{~N} \_$Phy means the $\delta^{15} \mathrm{~N}$ values of phytoplankton; $\delta^{15} \mathrm{~N} \_Z$ Zo means the $\delta^{15} \mathrm{~N}$ values of zooplankton;

$\delta^{13} \mathrm{C} \_$Sub means the $\delta^{13} \mathrm{C}$ values of submerged macrophyte; $\delta^{15} \mathrm{~N} \_$Sub means the $\delta^{15} \mathrm{~N}$ values of submerged macrophyte)

本次调查中, 滇东地区湖泊沉水植物 $\delta^{13} \mathrm{C}\left(-18.32 \% 0 \sim-5.98 \%\right.$ ) 与 Keely 等 ${ }^{[34]}$ 、黄亮等 ${ }^{[17]}$ 研究发现的水生植 物 $\delta^{13} \mathrm{C}(-50 \%$ - 11\% $)$ 相比总体偏正. 这可能反映了云南高原主要由二叠系和三叠系碳酸盐岩组成, 河湖 水化学性质由 $\mathrm{CO}_{3}^{2-}$ 控制 ${ }^{[35]}$, 当碳酸盐岩、水以及 $\mathrm{CO}_{2}$ 发生反应时生成 $\mathrm{Ca}^{2+}$ 和 $\mathrm{HCO}_{3}^{-}$, 所以 $\delta^{13} \mathrm{C}$ 值偏正的碳酸 盐岩碳源可能是导致喀斯特地区沉水植物 $\delta^{13} \mathrm{C}$ 值更为富集的重要原因.

滇东地区湖泊浮游植物的 $\delta^{13} \mathrm{C}$ 值比沉水植物偏负, 指示水体中浮游植物的碳源虽与沉水植物相似, 但 由于浮游植物具有迁移能力 ${ }^{[36]}$, 能够自由吸收更多容易吸收的 $\mathrm{CO}_{2}$ 作为碳源, 因此其 $\delta^{13} \mathrm{C}$ 值相对沉水植物 的偏负. 但滇东地区湖泊浮游植物 $\delta^{13} \mathrm{C}$ 值整体比西南地区其他区域显著偏正 ${ }^{[37]}$, 可能反映了本地区湖泊浮 游植物优势种的组成影响了其碳稳定同位素的分布特征. Wang 等 ${ }^{[37]}$ 调查发现, 贵州喀斯特水库中夏季浮游 植物 $\delta^{13} \mathrm{C}$ 值在 $-31 \% 0 \sim-18 \%$ 之间, 当湖泊浮游植物群落中硅藻占优势时, 浮游植物 $\delta^{13} \mathrm{C}$ 值更加偏负; 当湖 泊浮游植物群落中蓝藻、绿藻占优势时, 浮游植物 $\delta^{13} \mathrm{C}$ 值偏正. 本次滇东 10 个湖泊均为夏季集中采样, 浮游 植物中蓝藻、绿藻所占比例偏大, 导致了浮游植物 $\delta^{13} \mathrm{C}$ 值出现相对偏正的特征. 此外, 浮游动物作为初级消 费者大多以浮游植物为食, 因此浮游植物碳稳定同位素的组成和变化会直接影响浮游动物碳稳定同位素信 号. 研究区中浮游动物与浮游植物具有显著相似的 $\delta^{13} \mathrm{C}$ 值, 说明滇东地区湖泊中消费者浮游动物与其食物 (浮游植物) 在食物链传递过程中碳同位素分馏效应不显著.

本研究中滇东 10 个湖区浮游动物 $\delta^{15} \mathrm{~N}$ 显著高于浮游植物 $(P<0.05)$, 表明在食物链的能量传递过程中 氮同位素存在显著的分馏过程. 经典水生动物食性研究表明, 消费者 $\delta^{15} \mathrm{~N}$ 与食物相比约增加 $3 \% 0 \sim 5 \%$ (平 均为 $3.0 \% 0 \pm 2.6 \%)^{[38]}$. 本研究中主要的浮游动物个体偏小, 以桡足类的剑水蚤、哲水蚤和枝角类的象鼻溞 为主, 且都是滤食性浮游动物, 从水中滤食细小的浮游植物、细菌、碎屑等 ${ }^{[39]}$, 导致浮游动物氮同位素存在明 显的富集效应. 但在不同湖泊中富集效应存在一定的差异性, 可能反映了个别湖泊大个体浮游动物丰度较 
高, 而大个体浮游动物的氮同位素比小个体浮游动物更为富集, 因为某些大个体浮游动物 (如剑水蚤) 是捕 食性浮游动物 ${ }^{[40]}$, 因此存在氮同位素信号与食物链营养级上的差异. 上述分析表明, 滇东湖泊生态系统中 相邻营养级之间的碳同位素信号较为相似, 而氮同位素存在明显的分馏效应且平均富集系数为 $3.46 \%$, 与北 美温带地区的氮同位素富集系数 (3.4\% $)$ 基本一致 ${ }^{[41]}$.

\section{2 碳、氮稳定同位素信号的空间变化与影响因子识别}

在环境因子对同位素信号分布的影响上, 部分营养水平低的湖泊中浮游动物表现为比浮游植物相对富 集的 $\delta^{13} \mathrm{C}$ 信号, 反映了营养水平低的湖泊中外源碳对浮游动物的碳源产生了较大影响. 前人研究发现, 贫营 养湖泊中外源有机碳对浮游动物碳源的贡献量较高 (如 $22 \% \sim 75 \%{ }^{[42]}$ ), 较大程度地影响了湖泊中食物网结 构 ${ }^{[43]}$, 因此在贫营养湖泊中浮游动物和浮游植物两者间的 $\delta^{13} \mathrm{C}$ 值存在一定的相异性, 即浮游动物 $\delta^{13} \mathrm{C}$ 值较 浮游植物更为富集 (图 4). 然而, 在富营养湖泊中, 浮游动物碳源主要受到内源碳 (如浮游植物) 的影响 ${ }^{[44]}$, 导致在有机碳传输过程中两者之间较强的耦合作用与显著相似的 $\delta^{13} \mathrm{C}$ 值.

在空间分布上, 浮游植物的 $\delta^{13} \mathrm{C}$ 值受水温的影响最为明显 (图 5a), 如水温偏高的大屯海、长桥海和差 黑海中浮游植物的 $\delta^{13} \mathrm{C}$ 值相对其他湖泊偏正. 随着湖泊水温的升高, 水体中溶解 $\mathrm{CO}_{2}$ 减少 ${ }^{[45]}$, 浮游植物更 多地利用水体中 $\mathrm{HCO}_{3}^{-}$等无机碳源, 导致浮游植物碳 $\delta^{13} \mathrm{C}$ 值偏正并使得浮游动物 $\delta^{13} \mathrm{C}$ 值也间接受控于水体 水温. 同时,浮游动物的 $\delta^{13} \mathrm{C}$ 值还受采样点水深影响. 湖泊水深的不同可以导致栖息地等生物生境分布的 差异, 从而影响底栖与浮游类型的碳源贡献比例和食物网有机碳源的组成 ${ }^{[45]}$. 在水深较浅的采样点, 浮游 动物碳源以底栖碳源为主, $\delta^{13} \mathrm{C}$ 值偏正 ${ }^{[46-47]}$; 而水较深的采样点, 浮游植物等碳源对浮游动物的贡献占主 导. 同时, 浮游生物的 $\delta^{15} \mathrm{~N}$ 值也受到湖泊营养水平的显著影响. 云南高原湖泊农村面源污染基本上占人湖 污染物总量的 30\% 50\% ${ }^{[48]}$, 种植业、蓄禽养殖业和农村生活污水排放导致云南高原湖泊水体 TN 浓度升 高. 由于氨的挥发以及硝化作用,动物排泄物或生活污水最终形成 $\delta^{15} \mathrm{~N}$ 值高达 $10 \% \sim 20 \%$ 的 $\mathrm{NO}_{3}^{-[49-50]}$, 这些 $\delta^{15} \mathrm{~N}$ 值显著偏正氮盐的持续输人, 直接导致湖泊生态系统中水体与生物体内氮含量和 $\delta^{15} \mathrm{~N}$ 值偏高. Cole 等 ${ }^{[51]}$ 和 Udy 等 ${ }^{[52]}$ 的研究发现, 水生植物氮同位素值随着流域污水和水体中 DIN (溶解无机氮) 浓度的增加 而偏正. 滇东的长桥海、大屯海、杞麓湖和星云湖等湖泊由于长期接收流域污染 ${ }^{[21-22]}$, 湖泊水体 TN 浓度高、 富营养化较为严重, 导致生物体内 $\delta^{15} \mathrm{~N}$ 值偏正; 而差黑海、月湖、长湖等湖泊接收流域污染负荷较少、水体 $\mathrm{TN}$ 浓度较低 ${ }^{[21]}$, 因此湖泊生物体内的氮稳定同位素信号相对偏负. 同时, 富营养湖泊中常出现有机质的大 量分解和溶解氧水平的降低, 导致沉积物中微生物的反硝化作用增强, 可以产生较强的氮同位素分馏作 用 ${ }^{[49]}$. 较轻的氮同位素随反硝化作用生成的氮气而释放,剩余水体氮库中重同位素比例的增加可以导致水 体中 $\delta^{15} \mathrm{~N}$ 值偏正, 从而造成富营养化水体中湖泊生物氮同位素信号的富集.

沉水植物碳稳定同位素在空间分布上与湖泊透明度相关, 而透明度与湖泊藻类生物量存在密切的关系. 在贫营养湖泊中, 藻类生物量低且水体透明度较高, 同时藻类吸收利用水体中溶解性 $\mathrm{CO}_{2}$ 的强度小. 因此, 沉水植物能够较好地吸收水体中碳同位素较轻的溶解性 $\mathrm{CO}_{2}$, 从而导致沉水植物 $\delta^{13} \mathrm{C}$ 值呈现偏负的特征. 另外, 沉水植物 $\delta^{13} \mathrm{C}$ 值的变化还与沉水植物种类 ${ }^{[16]}$ 、光合途径 ${ }^{[53]}$ 、植株本身的生长速率 ${ }^{[54]}$ 等因素有关. 与 浮游生物类似, 沉水植物氮同位素信号还受水体染污物来源、 TN 浓度和反硝化作用强度的影响, 如沉水植 物氮同位素值偏正可能反映了流域污水 $\delta^{15} \mathrm{~N}$ 值的偏高和溶解性无机氮浓度的增加.

\section{3 水生生物 $C 、 N$ 元素含量和 $\mathrm{C} / \mathrm{N}$ 比值的分布特征及其与环境的关系}

云南东部地区湖泊生物对比结果表明, 不同门类生物体内具有不同的元素含量特征. 其中, 高等水生植 物 $\mathrm{C}$ 元素含量显著高于浮游植物和浮游动物, 反映了不同种类湖泊生物具有差异性的生理生态特征. 水生 植物系维管束植物, 碳是构成植物有机体的主要元素, 植物体内与 C 元素结合的化合物占植物干物质重量 的 $90 \%$ 以上 ${ }^{[55]}$, 使得水生植物 C 元素含量普遍较高. 浮游植物由藻类细胞组成, 具有纤维和其他多糖组成 的细胞壁, 而枝角类、桡足类等甲壳类浮游动物的个体主要由几丁质和碳酸钙组成 ${ }^{[56]}$, 导致浮游植物和浮游 动物 $\mathrm{C}$ 元素含量较水生植物偏低. 其次, 浮游生物体内主要由蛋白质、脂肪、核酸等构成 ${ }^{[57]}$, 所以浮游生物 个体的 $\mathrm{N}$ 元素含量普遍高于水生植物. 与长江中下游地区湖泊调查结果相比 ${ }^{[17]}$, 云南湖泊沉水植物 $\mathrm{C} 、 \mathrm{~N}$ 元 素相对含量总体偏高, 可能反映了云南湖泊水体受富含 $\mathrm{CO}_{3}^{2-}$ 组分的喀斯特基岩影响, 使得植物体内的 $\mathrm{C}$ 含 量偏高, 并导致水生植物吸收水体等环境中相应比率的 $\mathrm{N}$ 等营养元素 ${ }^{[58]}$. 同时, 水生植物叶片中的 $\mathrm{N}$ 是光 
合速率良好的指示物 ${ }^{[59]}$, 可能也反映了低纬高原地区较长的生长季节并促进了水生植物对营养元素的 吸收.

大量研究结果表明, 水生维管束植物的 $\mathrm{C} / \mathrm{N}$ 比值总体分布在 12.6 18.5, 而浮游生物 $\mathrm{C} / \mathrm{N}$ 比值大体分 布于 $6 \sim 8^{[60]}$. 类似地, 滇东湖泊群中高等水生植物 $\mathrm{C} / \mathrm{N}$ 比值明显高于浮游生物, 其中沉水植物和漂浮植物 的 $\mathrm{C} / \mathrm{N}$ 平均值分别为 18.39 和 15.67 , 而浮游植物和浮游动物平均值分别为 7.68 和 6.90 . 大量现代调查和沉 积物研究中, 湖泊有机物 $\mathrm{C} / \mathrm{N}$ 比值常被用于区分陆生和水生有机物来源 ${ }^{[61]}$. 本次调查结果表明, 云南高原 湖泊水生植物和浮游生物的 $\mathrm{C} / \mathrm{N}$ 比值均小于 20 , 该阈值可以可靠地指示湖泊有机质的内源贡献, 并为识别 该地区湖泊沉积物记录中内源有机质的长期影响和贡献率提供重要的科学依据.

\section{4 结论}

1) 滇东地区 10 个湖泊的空间调查显示, 水生植物和浮游生物对碳源的利用途径不同是导致其碳稳定 同位素分布差异的主要因素, 其中浮游动物与浮游植物的 $\delta^{13} \mathrm{C}$ 显著相关. 同时, 浮游动物的 $\delta^{15} \mathrm{~N}$ 信号比初 级生产者显著富集 (富集系数约为 $3.46 \%$ ) , 反映了湖泊食物网中氮同位素的分馏效应较为明显.

2) 空间分布上,浮游植物碳同位素组成受水温与水深等环境因子的显著影响. 在营养水平较低的湖泊 中, 浮游动物受外源有机碳的影响较大, 其 $\delta{ }^{13} \mathrm{C}$ 信号较浮游植物相对富集; 而在富营养湖泊中, 浮游动物以 浮游植物为主要食物来源, 有机碳传输过程中两者的耦合关系增强而呈现更为相似的 $\delta^{13} \mathrm{C}$ 值. 同时, 沉水植 物 $\delta^{13} \mathrm{C}$ 值则与水体透明度和 Chl. a 浓度等特征相关. 另外, 湖泊生物的 $\delta^{15} \mathrm{~N}$ 值均受水体富营养化程度的影 响,同时富营养化湖泊中反硝化作用的增强也可能产生了一定影响.

3) 滇东地区具有广泛分布的喀斯特地质背景, 可能导致了湖泊生物体内的 $\mathrm{C} 、 \mathrm{~N}$ 元素含量总体高于长江 中下游等其他地区. 同时,云南高原湖泊水生植物和浮游生物的 $\mathrm{C} / \mathrm{N}$ 比值都小于 20 , 同时两者呈现差异性 的分布特征.

4) 在识别了云南东部地区湖泊典型水生生物稳定同位素信号与元素组成的分布模式基础上,仍需进一 步结合其季节变化特征并从生物群落组成上甄别出碳源变化与生物地球化学循环的驱动机制, 可为云南湖 泊的生态系统评价与生态修复提供重要的科学依据.

\section{5 参考文献}

[ 1 ] Li SJ, Dou HS, Shu JH et al. Water environmental problems of lakes and water ecosystem recovery in China. China Water Resources, 2006, 13: 14-17. [李世杰, 窦鸿身, 舒金华等. 我国湖泊水环境问题与水生态系统修复的探讨. 中国水 利, 2006, 13: 14-17.]

[ 2 ] Qin BQ, Xu H, Dong BL et al eds. The principle and practice of eutrophic lake pestoration and management. Beijing: Higher Education Press, 2011. [秦伯强, 许海, 董百丽等. 富营养化湖泊治理的理论与实践. 北京: 高等教育出版 社, 2011.]

[ 3 ] Wang XM, Jin XQ, Xing XL et al. Effects of macrophyte on the lake ecosystem. Journal of Shandong Science, 2007, 20 (2) : 29-32. [王兴民, 金许秋, 邢晓丽等. 水生高等植物对湖泊生态系统的影响. 山东科学, 2007, 20(2): 29-32.]

[ 4 ] Benedict CR, Scott JR. Photosynthetic carbon metabolism of a marine grass. Plant Physiology, 1976, 57: 876-880. DOI: 10.1104/pp.57.6.876.

[ 5 ] Benedict CR, Wong W. Fractionation of the stable isotopes of inorganic carbon by seagrasses. Plant Physiology, 1980, 65: 512-517. DOI: $10.1104 /$ pp.65.3.512.

[ 6 ] Heck KL, Able KW, Roman CT. Composition, abundance, biomass, and production of macrofauna in a new England estuary comparisons among eelgrass meadows and other nursery habitats. Estuaries, 1995, 18(2): 379-389. DOI: 10. 2307/1352320.

[ 7 ] Rong W, Dearing JA, Langdon PG. Flickering gives early warning signals of a critical transition to a eutrophic lake state. Nature, 2012, 492(7429) : 419-422. DOI: 10.1038/nature11655.

[ 8 ] Marten S, Steve C, Foley JA et al. Catastrophic shifts in ecosystems. Nature, 2001, 413 (6856) : 591-596. DOI: 10. $1038 / 35098000$. 
[ 9 ] Legende L, Rivkin RB. Planktonic food webs: Microbial hub approach. Marine Ecology Progress Series, 2008, 365: 289 309. DOI: $10.3354 /$ meps07467.

[10] Fanelli E, Cartes JE, Papiol V. Food web structure of deep-sea macrozooplankton and micronekton off the catalan slope: Insight from stable isotopes. Journal of Marine Systems, 2011, 87: 79-89. DOI: 10.1016/j.jmarsys.2011.03.003.

[11] Li ZY, Jin XS, Zhuan ZM et al. Applications of stable isotope techniques in aquatic ecological studies. Acta Ecologica Sin$i c a, 2005,25$ (11) : 3052-3059. [李忠义, 金显仕, 庄志猛等. 稳定同位素技术在水域生态系统中的应用. 生态学 报, 2005, 25(11): 3052-3059.]

[12] Peterson BJ. Stable isotopes as tracers of organic matter input and transfer in benthic food webs: A review. Acta Oecologi$c a, 1999,20$ (4) : 479-487. DOI: 10.1016/S1146-609X(99)00120-4.

[13] Hobson KA, Welch HE. Determination of trophic relationships within a high arctic marine food web using $\delta^{13} \mathrm{C}$ and $\delta^{15} \mathrm{~N}$ analysis. Marine Ecology Progress Series, 1992, 84: 9-18.

[14] Grey J. Stable isotope analysis of the origins of zooplankton carbon in lakes of differing trophic state. Oeologia, 2000, 123: 232-240. DOI: 10.1007/s004420051010.

[15] Ngochera MJ, Bootsma HA. Temporal trends of phytoplankton and zooplankton stable isotope composition in tropical lake Malawi. Journal of Great Lakes Research, 2011, 37: 45-53. DOI:10.1016/j.jglr.2010.09.004.

[16] Wen ZR, Xu J, Xie P et al. Carbon and nitrogen stable isotopes of macrophytes from Lake Taihu. J Lake Sci, 2016,28 (1) : 163-169. DOI:10.18307/2016.0119. [温州瑞, 徐军, 谢平等. 太湖高等水生植物稳定碳、氮同位素特征. 湖泊 科学, 2016, 28(1): 163-169.]

[17] Huang L, Wu Y, Zhang J et al. Distribution of C, N, P and $\delta^{13} \mathrm{C}$ in aquatic plants of some lakes in the middle Yangtze valley. Acta Geoscien Tica Sinica, 2003, 24: 515-518. [黄亮, 吴荣, 张经等. 长江中游若干湖泊水生植物体内 C、N、 $\mathrm{P}$ 及 $\delta^{13} \mathrm{C}$ 分布. 地球学报, 2003, 24:515-518.]

[18] Xu J. Ecological studies on the food web structures and trophic relationships offreshwater lakes in China using stable carbon and nitrogen isotopes [Dissertation]. Wuhan: Institute of Hydrobiology, Chinese Academy of Sciences, 2005. [徐军. 应 用碳-氮稳定性同位素探讨淡水湖泊的食物网结构和营养级关系 [学位论文]. 武汉: 中国科学院水生生物研究 所, 2005.]

[19] Yunnan Bureau of Geology and mineral resources ed. Regional geology of Yunnan Province. Beijing: Geological Publishing House, 1990. [云南省地质矿产局. 云南省区域地质志. 北京: 地质出版社, 1990. ]

[20] Xu LH, Jiang CL. Actinomycetes in six lakes in central and south Yunnan. Acta Hydrobiological Sinica, 1987, 11(3): 274-277. [徐丽华, 姜成林. 滇中南六湖的放线菌. 水生生物学报, 1987, 11(3): 274-277.]

[21] Yang L, Li H eds. Yunnan wetlands. Beijing: China Forestry Publishing House, 2009: 11. [杨岗, 李恒. 云南湿地. 北 京: 中国林业出版社, 2009: 11.]

[22] Liu YY, Chen GJ, Shi HB et al. Responses of a diatom community to human activities and climate changes in Xingyun Lake. Acta Ecologica Sinica, 2016, 36(10) : 3063-3073. [刘园园, 陈光杰, 施海彬等. 星云湖硅藻群落响应近现代 人类活动与气候变化的过程. 生态学报, 2016, 36(10): 3063-3073.]

[23] "Water and wastewater monitoring and analysis method" editorial board of State Environmental Protection Administration of China ed. Monitoring and analysis methods of water and wastewater: fourth edition. Beijing: China Environmental Science Press, 2002: 243-285. [ 国家环境保护总局《水和废水监测分析方法》编委会. 水和废水监测分析方法: 第 4 版. 北 京: 中国环境科学出版社, 2002: 243-285.]

[24] Qian SS ed. Environmental and ecological statistics with R. Boca Raton: CRC Press, 2010.

[25] Robert IK ed. R in action: Data analysis and graphics with R. Greenwich: Manning Publications, 2011.

[26] Shu JH. Discussion on evaluation method of lake eutrophication in China. Environmental Pollution Control, 1990, 12(5): 2-6. [ 舒金华. 我国湖泊富营养化程度评价方法的探讨. 环境污染与防治, 1990, 12(5) : 2-6.]

[27] Wu X, Yang XE, Li TQ. Study on purified efficiency of phosphorus and nitrogen from eutrophicated sight water by several floating macrophytes. Journal of Soil and Water Conservation, 2007, 21 (5): 128-132. [ 吴湘, 杨肖娥, 李廷强. 漂浮植 物对富营养化景观水体的净化效果研究. 水土保持学报, 2007, 21(5): 128-132.]

[28] Smith BN, Samuel E. Two categories of ${ }^{13} \mathrm{C} /{ }^{12} \mathrm{C}$ ratios for higher plants. Plant physiology, 1971, 47(3) : 380-384. DOI: org/10.1104/pp.47.3.380.

[29] Li J. Accumulation of heavy metals in submerged macrophytes [Dissertation]. Kunming: Kunming University of Science 
and Technology, 2009. [李晋. 沉水植物对重金属铜的富集研究 [学位论文]. 昆明理工大学, 2009.]

[30] Yang QX. Study on the competition between submerged macrophytes and planktonic algae in eutrophic water. J Lake Sci, 1996, 8(1) : 17-24. DOI: 10.18307/1996.sup03. [ 杨清心. 富营养水体中沉水植物与浮游藻类相互竞争的研究. 湖 泊科学, 1996, 8(1): 17-24.]

[31] Zhuang YY, Zhao F. Restraint effect of higher aquatic plants on algae growth. Environmental Science Survey, 1995, 3(6) : 44-49. [ 庄源益, 赵凡. 高等水生植物对藻类生长的克制效应. 环境科学导刊, 1995, 3(6) : 44-49.]

[32] Bain JT, Proctor M. The requirement of aquatic bryophytes for free $\mathrm{CO}_{2}$ as an inorganic carbon source: sone experimental evidence. New Phytologist, 1980, 86(4) : 393-400.

[33] Raven J. Exogenous inorganic carbon sources in plant photosynthesis. Biological Reviews, 1970, 45(2) : 167-220. DOI: 10.1111/j.1469-185X.1970.tb01629.x.

[34] Keely JE, Sandquist DR. Carbon: Freshwater plants. Plant Cell Environment, 1992, 15: 1021-1035. DOI: 10.1111/j. 1365-3040.1992.tb01653.x/epdf.

[35] Liu CQ ed. Earth surface biogeochemical processes and mass cycles: karstic catchment erosions and bioelements cycles in Southwest China. Beijing: Science Press, 2007.

[36] Giorgio D, France RL. Ecosystem-specific patterns in the relationship between zooplankton and POM ormicroplankton $\delta^{13}$ C. Limnology and Oceanography, 1996, 41(2) : 359-365. DOI: 10.4319/lo.1996.41.2.0359.

[37] WangBL, Liu CQ, Xi P. Mechanisms controlling the carbon stable isotope composition of phytoplankton in karst reservoirs. Limnol, 2013, 72(1):127-139.

[38] Deniro MJ, Epstein S. Influence of the diet on the distribution of nitrogen isotopes in animals. Geochim Cosmochim Acta, 1981, 45: 341-351.

[39] Institute of Animal, Chinese Acdemy of Science, Crustaceans Research Group ed. Chinese animal. Beijing: Science Press, 1979. [中国科学院，中国动物志委员会. 中国动物志. 北京: 科学出版社, 1979.]

[40] Zhang ZS, Huang XF eds. Research methods of freshwater plankton. Beijing: Science Press, 1991. [章宗涉, 黄祥飞. 淡 水浮游生物研究方法. 北京: 科学出版社, 1991.]

[41] Post DM. Using stable isotopes to estimate trophic position: models, methods, and assumptions. Ecology, 2002, 83: 703 718. DOI: $10.1890 / 0012-9658$ (2002) 083[0703: USITET $] 2.0 . \mathrm{CO} ; 2$.

[42] Yokokawa T, Nagata T. Linking bacterial community structure toarbon fluxes in marine environments. Journl of Oceanography, 2010, 66(1) : 1-12. DOI: 10.1007/s10872-010-0001-4.

[43] Wetzel RG. Limnology: Lake and river ecosystems. Eos Transactions American Geophysical Union, 2001, 21(2): 1-9. DOI: 10.1016/B978-0-08-057439-4.50017-4.

[44] Grey J. Stable isotope analysis of the origins of zooplankton carbon in lakes of differing trophic state. Oecolo Gia, 2000, 123: 232-240. DOI: 10.1007/s004420051010.

[45] Hutchinson GE ed. A treatise on limnology, Vol I: Geography, physis and chemistry. New York: John Wiley and Sons, 1957.

[46] Kalff J. Limnology. Prentice Hall, Upper Saddle River, NJ. Benjamin Cummings, 2002.

[47] France RL. Differentiation between littoral and pelagic food webs in lakes using stable carbon isotopes. Limnology and Oceanography, 1995, 40: 1310-1313.

[48] Sun ZX. Primary study on prevention and control of agricultural pollution in Yunnan Plateau Lake. China Lake Forum, 2011. [孙治旭. 云南高原湖泊农业而源污染防治方法初探. 中国湖泊论坛, 2011.]

[49] Heaton T. Isotopic studies of nitrogen pollution in the hydrosphere and atmosphere: a review. Chemical Geology: Isotope Geoscience Section, 1986, 59: 87-102.

[50] Kreitler CW, Jones DC. Natural soil nitrate: The cause of the nitrate contamination of ground water in Runnels County, Texasa. Ground Water, 1975, 13(1) : 53-62.

[51] Cole ML, Valiela I, Kroeger KD et al. Assessmental of a $\delta^{15} \mathrm{~N}$ isotopic method to indicate anthropogenic eutrophication in aquatic ecosystems. Journal of Environmental Quality, 2004, 33: 124-132. DOI: 10.2134/jeq2004.1240.

[52] Udy JW, Dennison WG. Growth and physiological responses of three seagrass species to elevated sediment nutrients in Moreton Bay, Australia. Journal of Experimental Marine Biology and Ecology, 1997, 217 : 253-277.

[53] Farquhar GD, Richards RA. Isotopic composition of plant carbon correlates with water-use efficiency of wheat genotpes. 
Australian Journal of Plan Physiology, 1984, 11: 539-552.

[54] Deines P. The carbon isotopic composition of diamonds: relationship to diamond shape, color, occurrence and vapor composition. Geochimicaet Cosmochimica Acta, 1980, 44(7) : 943-961. DOI: 10.1016/0016-7037(80)90284-7.

[55] Kandall C, Silva SR, Kelly VJ. Carbon and nitrogen isotopic compositions of particulate organic matter in four large systems across the United States. Hydrol Process, 2011, 15: 1301-1346. DOI: 10.1002/hyp.216.

[56] Christer B, Lars-Anders H, Han BP eds. The biology of lakes and ponds. Beijing: Higher Education Press, 2013 : 4. [Christer Bronmark, Lars-Anders Hansson, 韩博平. 湖泊与池塘生物学. 北京: 高等教育出版社, 2013: 4.]

[57] Wang JL, Li SP eds. Environment in microbiology. Beijing: Higher Education Press, 2004: 1. [王家玲, 李顺鹏. 环境 微生物学. 北京: 高等教育出版社, 2004: 1.]

[58] Liu X, Zhang Y, Han W et al. Enhanced nitrogen deposition over China. Nature, 2013, 494: 459-462. DOI: 10.1038/ nature11917.

[59] Field C, Mooney HA eds. The photosynthesis nitrogen relationship in wild plants. On the economy of plant from and function. Cambridge: Cambridge University Press, 1986: 25-55.

[60] Lu FY, Liu ZQ, Ji HB. Carbon and nitrogen isotopes analysis and sources of organic matter in the upper reaches of the Chaobai River. Science China: Earth Sciences, 2012, 42(12) : 1912-1922. [卢凤云, 刘竹青, 季宏兵. 潮白河上游有 机质的碳、氮稳定同位素分析及来源探讨. 地球科学, 2012, 42(12) : 1912-1922.]

[61] Meyers PA, Leenheer M, Bourbonniere R. Diagenesis of vascular plant organic matter components during burial in lake sediments. Aquatic Geochem, 1995, 1: 35-52. DOI: 10.1007/BF01025230. 